\title{
Work-integrated Digital Learning Experiences and Students' Efficacy for Online Journalism Work
}

\author{
${ }^{1}$ Joseph Njuguna, ${ }^{1}$ Hellen K Mberia, ${ }^{2}$ Margaret Jjuuko \\ ${ }^{1}$ Jomo Kenyatta University of Agriculture and Technology, Kenya \\ ${ }^{2}$ University of Rwanda, Rwanda
}

\begin{abstract}
With shrinking newsrooms and dynamic media landscapes, the onus of journalism programs is to deliver graduates with work-ready practical skills. Like in other countries, Rwandan media training institutions continue to leverage work-based learning experiences to bridge practical skills gaps evident among students as they transition to the workplace. However, in an online-driven marketplace, there is paucity of research on the role of such work-based learning in developing students'self-efficacy for the professional online skills. To address this research gap, this study explores how mass communication students perceive work-based learning and its relationship with their self-efficacy for online journalism work. Survey data was gathered from a sample of 143 students systematically drawn from universities. These universities were selected as the only ones offering mass communication programs in Rwanda as at the time of the study. Descriptive results showed that the respondents considered themselves highly efficacious in the different online journalism skills being measured. The students' industry experiences, digital class-based practicums and contacts with professionals were found to have positive and significant correlation with their efficacy for online journalism skills. The null hypothesis was disconfirmed by the regression analysis results which indicated a significant $27.8 \%$ contribution of workintegrated learning experiences in explaining the students' online journalism efficacy beliefs. The findings of this study not only contributes to better understanding of the role of digital skills exposure through field experience in promoting the workreadiness of the future professionals, but also points to the urgency of integrating such experiences in online skills training.
\end{abstract}

\section{Introduction}

A critical challenge facing higher learning institutions has been to produce graduates who meet the needs of the increasingly dynamic work environment. With a gradual shift to converged workplaces, most industries now prioritize graduates who are multi-skilled and can demonstrate practical technical ability in performing most tasks [1]. To address this lacuna, most universities have taken to practical approaches such as work-integrated learning in their curricula to immerse students in the working of the industry before they graduate.

The essence of this work-integrated learning is to 'incorporate workplace based component' and 'bridge the students' academic present and their professional future' $[10,1]$. These experiences foster meaningful education which not only enhances the students' awareness of different work relationships but also encourages their career aspirations. They also deepen the students' knowledge and comprehension of the real world of work eventually building their competence in similar jobs upon graduation. Furthermore, learning from real-life scenarios facilitates the creation of authentic, value-added experiences which gradually build the professional character of the future professionals [9]. Significant evidence shows that the benefits of work-based learning extend beyond the development of technical job-specific skills to soft skills such as communication, teamwork, work ethics and problem-solving skills [2, 3].

While the dimensions of work-integrated learning in domains like journalism and communication have not been comprehensively identified, scholars seem to converge on a framework that underscores the importance of systematic practical training, for example through journalism apprenticeships; structured work experiences that expose students to professional journalism practice and fieldwork; in-class media practicums that draw from industry examples as well partnerships between educational institutions and 
the media industry to develop mutually beneficial solutions [9]. Emerging literature shows that scarce attention has been paid to the journalism and communication domain, especially on how such workbased learning experiences systematically relate to the development of efficacy beliefs for professional work $[3,9]$.

Although the role of field-based learning in affording opportunities for students' work readiness is no longer doubted, the specific roles of work-based learning strategies such as journalism internships, volunteer opportunities, class-based practicums and self-development through online platforms (e.g blogs) in online skills efficacy development have not been empirically tested.

This study, therefore, endeavors to fill this void by exploring how different dimensions of work-related learning play into media students' efficacy beliefs for online journalism skills in Africa context, specifically Rwanda. The next sections explore literature on online journalism skills, with an empirical review of relevant studies on work-integrated learning in the journalism and communication context. A discussion on selfefficacy and experiential learning theoretical framework as they relate to this study then follows. The methods are then discussed, followed with findings and implications for the study.

\section{Literature review}

\subsection{Online journalism skills for work readiness}

With dynamic communication environments brought by advances in new media technologies, identifying a definite digital skill set with which to assess graduates' online readiness while joining the industry has been arduous. In the context of online journalism (producing news stories in different platforms for online audiences), debates still rage on the range of requisite 'online' skills that media training institutions should be teaching, giving the shifting nature of information tastes and preferences for news media audiences. With no comprehensive catalogue of such skills, most scholars fall back on generic digital competence frameworks which underscore the $21^{\text {st }}$ century skills, knowledge and attitudes required by professionals (in general) to effectively use new media technologies [4].

The lack of a specific unified online skills framework, for domains such as journalism, has been explained by the fluid nature of new media skills which gradually get replaced 'even before the old ones are clearly defined' [4]. However, evidence suggests that online readiness in modern-day workplaces implies the effective use of online tools (e.g. social media) to communicate with audiences, develop and share multimedia content, conduct online research, understand and employ ethical strategies in online interactions as well as use online tools to solve problems affecting the society. This aligns with Ferrari's digital competence framework [5] which attempted to consolidate views from several others, like Van Deursen and Van Dijk's who consider information navigation skills, social media skills and online creativity skills as crucial in preparing people for the work environment [4].

In the context of online journalism, it has been suggested that digital frameworks like Ferrari's can be contextualized to develop a catalogue of skills which could be used as yardstick to measure journalism students' digital readiness for the industry [6]. With the consensus that media students should be equipped with an array of competencies to understand the online environment and how it is changing the industry, the need for multi-skilled professionals (e.g who can create stories for multiple platforms) has become a priority. Specifically, researchers suggest that future professionals should demonstrate ability to create and edit stories on video and audio platforms, do web coding and use online applications such as social networking sites) to produce and distribute content to media audiences $[2,7,8]$.

\subsection{Work-integrated learning for industry preparedness}

Being a practical program, journalism education should provide and encourage opportunities for students to be creative and test the boundaries of their skills through fieldwork, volunteer jobs, extra trainings and practicums in the industry [2, 3]. Failure to adequately expose journalism students to work-based experiences has hindered their future productive professional lives, especially since most media training institutions do not have adequate technical facilities for training and practice [6]. Such experiences afford students opportunities to develop and integrate knowledge into practice as well as create new knowledge from the real work experiences.

It has been argued that since the perpetually changing media environment does not allow students to grasp the workings of the media 'through textbooks and lectures alone', they must link theory with practice through work-integrated learning experiences [7]. While such experiences have been touted to boost skills acquisition, professional networking and work self-efficacy of the students, some scholars recommend that their effectiveness is measured on the breadth and 
depth of practical skills gained in line with program objectives. In most cases, students attest to the value of work experiences in shaping their careers [6].

In her study on field work experiences of undergraduate communication students, Royal discovered that students felt more exposed to real practical issues that improved their perceived work readiness [10]. Some students reported on-the-job technology learning experiences which could not match what they had in class, while others argued that interacting with new technology tools on the work place made them realize how inadequate their digital skills were. In line with research evidence, students' perspectives seemed to suggest that the work environment provided the most credible measure of one's readiness to work. According to Royal, journalism students' value their practical field experiences more than class work, since the workplace challenges them to match up to expected skills when they begin their careers [10].

By students participating in experiential activities like publishing on the online newspaper or website, scholars like Jones consider this as an opportunity for students, not only to evaluate their professional readiness in real work situations, but also improve their critical thinking and communication skills. In effect, engaging in such experiential activities that simulate future career experiences provides students with authentic opportunities that create a connection between school and industry [2].

In the context of new media technologies, a heightened self of social media efficacy is developed when students set up their own social media accounts and actively use them. Moreover, when students engage in social media communication for real events, for example, institutional events, web updates, online sourcing, creation and sharing of real stories, etc. such contributes to the enactment of their mastery of professional experience as underscored by Bandura's social cognitive theory [4]. Also, consuming online content created by other professionals and contributing feedback to them helps to model behavior of the future professional who vicariously learns by observing and participating in the performance of those in the industry (8).

\subsection{Theoretical framework}

The foregoing anecdotal evidence on the value of work-integrated learning points to the urgent need for media training institutions to invest resources to ensure students get the right exposure for work readiness. Inspired by experiential learning theories such as Kolb's, the role of experience in formal learning is considered deliberate in the sense that one engages with it to critically reflect on how knowledge learnt can be transformed into practical application for professional purposes [12]. According to Kolb therefore, effective learning is underpinned by recognizing one's experiences and building on it to transform their behavior or perceptions of phenomena. With the learner being in direct touch with the realities or a phenomenon under study, Kolb asserts that theory is linked to industry expectations through this 'bridge of experience' (p.11) which in itself facilities the learning process [12].

In the digital skills learning context, Palilonis touts this theory as critical in explaining how learners can leverage digital work experiences in their professional growth. By interacting with online platforms in the real world of work, students get to derive meaning from direct authentic digital experiences and reflect on their ability to perform these skills after graduation [13]. Experiential learning supports a key tenet of selfefficacy theory propounded by Bandura that touts the mastery of experiences as the greatest contributor of positive beliefs (especially among future professionals) in the capacity to perform a given set of skills [11].

\subsection{Research context}

Like other developing countries, Rwanda's education system is beset by myriad problems of low teacher capacity, high student enrolments and scarcity of technical resources. Yet stakeholders continue to require universities to adopt authentic learning experiences that produce work-ready students upon graduation $[14,15]$.

In its 2016 policy on competence-based education, the Ministry of Education emphasizes the need for higher institutions of learning to embrace work-based learning experiences to facilitate students' readiness for the job market [16]. The media industry continues to decry the low capacity of graduating journalism and communication students and recommends that this gap be bridged by exposing students to practical experiences in emerging skills in the course of their studies.

In its review of the performance of the media industry in Rwanda, the Media High Council revealed that practitioners apportioned blame on poor performance on the kind of graduates it receives - most are not work-ready, with little or no practical experience but heavy on theory [14].

To address the academia-industry gap and as indicator of the increasing interest in work-based experiences, journalism schools have made attempts at integrating work-based learning (e.g. internships) in their curricula as the norm rather than exception. Some have also made attempts to collaborate with the industry to identify opportunities for field placements, 
student volunteerism, guest-speaking engagements as well as collaborations during curricula reviews. This exposure has resulted in favourable student feedback on the delivery of practical journalism skills in the schools [7].

\subsection{Study objectives and hypothesis}

While students' efficacy beliefs for technology use have been explored in different domains, scant attention has been paid on the media industry, more so among future professionals in the developing world. In Rwanda, the level of efficacy for online journalism work among mass communication students has not been explored. Further, the role played by workrelated experiences on this perceived efficacy merits investigation. This study endeavors to explore this gap by statistically testing the contribution of these experiences on the perceived online readiness of these students. The following two questions guided the study:

1. How efficacious are Rwandan mass communication students in performing online journalism skills, as adapted from Ferrari's (2012) digital competence scale?

2. Are work-based learning experiences significantly related to the perceived online journalism efficacy of the students?

The study tests the null hypothesis that postulate the non-existence of a significant relationship between the work-based learning experiences and the online journalism efficacy of the students.

\section{Methods}

The study targeted a population of 293 finalist journalism and communication students in five Rwandan universities. A sample of 182 students was selected using Yamane's formula for populations of less than 1500 [17], with 143 of these (79\%) returning the completed questionnaires. A researcher-constructed survey instrument gathered data about the students' gender and study option, their work-related learning experiences as well as perceived ability to perform online journalism work. The instrument, comprising 5point Likert scale response options for the independent and dependent variables (where 1=strongly disagree and $5=$ strongly agree), was piloted with a sample of students $(n=20$, i.e. four from each of the five schools) drawn randomly but respecting gender.

The Cronbach Alpha test indicated that the reliability of the instrument was 0.743 which met the threshold of 0.70 widely accepted in social sciences
[18]. The constructs were validated by a group of five online journalism educators and four professionals who appraised them for their appropriateness and relevance.

Students' online journalism efficacy was operationalized and measured using a scale adapted from Ferrari's digital skills scale considered as suitable measure for $21^{\text {st }}$ century digital skills for professionals [5]. The aspects measured under this scale were: online research skills, social media communication skills, multimedia content creation skills, online ethics and privacy skills and problem-solving with social media. The reliability estimates for the constructs under the study variables ranged between 0.721 and 0.083 , indicating the general fitness of the instrument. Before administering the instrument, the researcher briefed the students about the study objectives and gave assurance on the confidentiality of the responses. The students were also asked to volunteer and feel free to decline.

Descriptive statistics were used to analyse the respondents' patterns of work-related learning experiences and their efficacy for online journalism work. To further interrogate the nature of the relationships between the work-based learning dimensions and online journalism efficacy, inferential statistics (correlation and regression analyses) were run. To determine the significance of the results, the study hypothesis was tested at a 5\% level of probability.

\section{Findings}

\subsection{Work-based learning experiences}

Industry experiences were the practical works that respondents executed to address an online need in the industry during their fieldwork, volunteer or class times. The work-based digital learning experiences were operationalized as the online skills learnt from industrial experiences such as internships, online contributions to the industry during class or fieldwork and online interactions with significant others like practising journalists. Table 1 shows the crosstabulated results of the responses.

\section{Table 1. Response rates for work-based learning experiences}

\begin{tabular}{|c|c|c|c|c|c|c|}
\hline$\frac{\mathscr{E}}{\stackrel{n}{\sigma}}$ & Indicator & 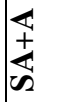 & Z & $\begin{array}{l}\text { 令 } \\
\stackrel{+}{0}\end{array}$ & $\sum$ & هُ \\
\hline 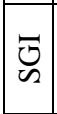 & $\begin{array}{l}\text { I learnt different } \\
\text { online skills during } \\
\text { my internship }\end{array}$ & 79 & 4.9 & 16.08 & 4.07 & 1.3 \\
\hline
\end{tabular}




\begin{tabular}{|l|l|l|l|l|l|l|}
\hline & $\begin{array}{l}\text { I participated in } \\
\text { online news } \\
\text { production for an } \\
\text { organisation }\end{array}$ & 52.4 & 18.9 & 28.67 & 3.38 & 1.3 \\
\hline $\begin{array}{l}\text { I did live online } \\
\text { coverage of an } \\
\text { event }\end{array}$ & 63.6 & 6.3 & 20.09 & 3.45 & 1.5 \\
\hline $\begin{array}{l}\text { I developed social } \\
\text { media accounts for } \\
\text { organisations }\end{array}$ & 35.7 & 14.1 & 50.38 & 2.72 & 1.4 \\
\hline $\begin{array}{l}\text { I contributed stories } \\
\text { to online news } \\
\text { media }\end{array}$ & 58.1 & 18.9 & 23.08 & 3.43 & 1.2 \\
\hline $\begin{array}{l}\text { Class practical work } \\
\text { involved actual } \\
\text { industry online } \\
\text { productions }\end{array}$ & 56.7 & 26.6 & 16.78 & 3.47 & 1.1 \\
\hline $\begin{array}{l}\text { I participated in } \\
\text { production of online } \\
\text { school newspaper }\end{array}$ & 47.6 & 11.2 & 41.28 & 3.11 & 1.5 \\
\hline \multirow{2}{*}{$\begin{array}{l}\text { I use the online } \\
\text { works of other } \\
\text { professionals to } \\
\text { improve my } \\
\text { journalistic skills }\end{array}$} & 86.7 & 9.8 & 3.5 & 4.34 & 0.8 \\
\hline & \begin{tabular}{l} 
Average \\
\hline
\end{tabular}
\end{tabular}

Key: SA = Strongly Agree; $\mathrm{A}=$ Agree; $\mathrm{N}=$ Neutral, $\mathrm{D}$ $=$ Disagree; $\mathrm{SD}=$ Strongly Disagree; $\mathrm{M}=$ Mean; s.d.=Standard Deviation; SGI=skills gained from industry; $\mathrm{SCI}=$ skills contributed to industry; LPC=learning from professional contacts.

To gauge the role of work-based learning in augmenting the online skills of respondents, combined results posted a $79 \%$ agreement $(M=4.07$, s.d.=1.298) among the respondents affirming having gained practical social media skills during their internships. Slightly more than $52 \%$ of the respondents also acquired hands-on skills in producing online stories for the host organizations, while $63.6 \%$ participated in the live online coverage of events like workshops (using Twitter, Skype, etc.) for some media organizations. This live coverage with social media would be instrumental in moving the respondents from the 'social' to 'professional' realm of using such tools in actual events.

Regarding personal contributions to the industry, the results showed that $58.1 \%(M=3.43$, s.d.=1.172) of the respondents regularly contributed to news production by sending unsolicited or solicited stories to online news sites. This is definitely a crucial measure of their online news writing efficacy, once their stories got published. When asked to indicate if they had helped to create social media profiles for organizations, only $35.7 \%$ of them $(M=2.72$, s.d.=1.441) affirmed having helped to create and maintain online professional profiles for organizations. This portrayed a gap in the respondents' contribution of promoting the use of online tools for organizational branding and interaction with clients regarded as crucial in organizational competitiveness.

Using real cases from the industry to develop online skills exercises at the classroom level was considered helpful in the students' online preparedness. $56.7 \%(\mathrm{M}=3.47$, s.d.=1.093 $)$ of the respondents thought that the class practicums had a practical industry focus implying that the exercises related well with the work they would eventually do in the industry upon graduation. Although scholarly journalism is touted as key in preparing students for the industry [10], few respondents participated in scholarly journalism outside class work (for example, contributing stories to school online magazine, online radio, etc). Results indicated that only $47.6 \%$ of them had actively participated in the online news production in their school media. With the majority of respondents $(86.7 \%)$ indicating that they regularly engaged other professionals through their online stories (e.g. reading, listening and watching stories), this seemed to suggest that they were in constant touch with the industry and possibly drew important lessons for the own preparedness.

In a nutshell, the average agreement response rate to the issues surrounding online work-related experiences of the respondents was $60.1 \% \quad(M=3.5$, s.d.=1.253) indicating that about $60 \%$ of these respondents generally considered work-based online learning experiences as contributing to their perceived industry readiness. The results related with previous research which supported 'real-world' projects or experiences for professional competence development.

According to Bandura, efficacy for doing a task is achieved through observing others performing, personal mastery of the skills or behavior, getting feedback (encouragement) on performed behaviours and developing a feeling or conviction that one can actually perform [11].

By participating in actual or simulated online production events or case studies, therefore, the respondents in this study seemed to gradually develop their beliefs in their capacity to execute online journalism in the industry upon graduation. According to Peach and Gamble, learning with authentic scenarios gives professional meaning to the direct experience gained [1]. These results pointed to a possible direct relationship between pre-employment exposure to online media tools and actual performance with the online tools. This aligns with a scholar like Jones who asserts that positive previous experiences (e.g. ease of use and effective results) with a technology is likely to lead to high efficacy beliefs in using the technology in the future [2]. 


\subsection{Descriptive analysis for online journalism efficacy}

As the dependent variable, efficacy for online journalism work was measured by responses on the respondents' beliefs in their general ability to conduct research online, produce multimedia content for online platforms, use different social media tools to communicate to audiences, observe online ethics and privacy as well as employ online tools to solve organization-audience problems. Table 2 shows the cross-tabulated results under this variable.

Table 2. Response rates for efficacy for online journalism skills

\begin{tabular}{|c|c|c|c|c|c|}
\hline $\begin{array}{l}\text { Online journalism } \\
\text { beliefs }\end{array}$ & $\sum_{\pi}^{+}$ & Z & $\begin{array}{l}0 \\
\text { 古 } \\
0\end{array}$ & $\Sigma$ & $\underset{\dot{s}}{\dot{s}}$ \\
\hline $\begin{array}{l}\text { I belief I can } \\
\text { effectively conduct } \\
\text { journalistic research } \\
\text { in different online } \\
\text { platforms }\end{array}$ & 84.4 & 12.1 & 3.5 & 4.2 & 0.8 \\
\hline $\begin{array}{l}\text { I belief I can use } \\
\text { different social media } \\
\text { tools to communicate } \\
\text { professionally }\end{array}$ & 76.8 & 12.9 & 10.3 & 4.0 & 1.0 \\
\hline $\begin{array}{l}\text { I belief I can produce } \\
\text { different multimedia } \\
\text { content and share it in } \\
\text { different social media } \\
\text { platforms }\end{array}$ & 73.7 & 15.0 & 11.3 & 4.0 & 1.0 \\
\hline $\begin{array}{l}\text { I belief I can apply } \\
\text { ethical online practices } \\
\text { when I publish stories } \\
\text { online }\end{array}$ & 80.4 & 15.0 & 4.6 & 4.2 & 0.9 \\
\hline $\begin{array}{l}\text { I belief I can use } \\
\text { different social media } \\
\text { tools to solve } \\
\text { organization or } \\
\text { audience problems }\end{array}$ & 85.3 & 9.9 & 4.8 & 4.2 & 0.8 \\
\hline Average & 81.1 & 13 & 6.9 & 4.1 & 0.9 \\
\hline
\end{tabular}

Key: SA = Strongly Agree; $\mathrm{A}=$ Agree; $\mathrm{N}=$ Neutral, $\mathrm{D}$ $=$ Disagree; $\mathrm{SD}=$ Strongly Disagree; $\mathrm{M}=$ Mean; s.d.=Standard Deviation

The results showed that most respondents had more than average efficacy levels in all the five online journalism skills. Particularly, their belief in the ability to use social media tools to solve organizationaudience problems attracted the highest aggregate level of agreement (Strongly Agree + Agree) rate (i.e. $85.3 \%$ ). Most respondents (84.4\%) also expressed high efficacy in their use of social media tools to conduct journalism research. Of the five skills assessed, the ability to produce and share multimedia stories across different online platforms had the lowest agreement rate $(73.7 \%)$. This implies that respondents did not consider themselves adequately prepared to develop news stories using a combination of text, sound and images for varied online audiences.

From the overall results, the respondents' average efficacy for all the online journalism tasks was $81.1 \%$. This meant that about 116 out of 143 (or four out of five of them) respondents considered themselves highly efficacious in the requisite online skills for professional journalists. While an aggregate of $13 \%$ expressed no inclination on their online efficacy levels, a paltry $6.9 \%$ (about 11 out of the 143 respondents) were not ready to perform tasks requiring the online skills assessed.

To prove the significance of these results when associated with work-based online learning experiences as the predictor variable, further statistical tests were done. The results and implications are shown in the next sections.

\subsection{Correlation analysis of work-based experiences and online journalism efficacy}

The intensity of the relationship between the students' work-based learning experiences and their online journalism efficacy was tested using the Pearson's Product moment correlation (r) analysis. Table 3 shows the correlation matrix results between the two categories of variables.

Table 3. Correlation between work-based experiences and online journalism efficacy

\begin{tabular}{|c|c|c|c|c|}
\hline \multicolumn{2}{|c|}{} & SGI & SCI & LPC \\
\hline $\begin{array}{c}\text { Online journalism } \\
\text { efficacy }\end{array}$ & $\mathrm{r}$ & $.444^{* *}$ & $.428^{* *}$ & $.328^{* *}$ \\
\cline { 2 - 5 } & $\begin{array}{c}\text { Sig. (2- } \\
\text { tailed) }\end{array}$ & .000 & .000 & .000 \\
\hline
\end{tabular}

Key: **. Significant at 0.01(2-tailed); SGI=skills gained from industry; SCI=skills contributed to industry; LPC=learning from professional contacts.

To interpret the resulting correlation coefficients, Cohen's rules of thumb were employed where a predictor-criterion correlation coefficient value between -0.3 and $+0.3=$ weak correlation, between 0.3 and $0.5=$ moderate correlation, between 0.5 and $0.9=$ strong correlation and; a value between 0.9 and $1.0=$ very strong association [19]. Results indicated that all the dimensions of work-based learning experiences had positive but moderate correlations with the online journalism efficacy beliefs of the students. Furthermore, all relationships were highly significant at $95 \%$ confidence level. The strongest positive correlation was found between the nature and types of online skills gained from the industry $(r=.444$, $p-$ value $<0.05$ ), followed by the students' contributions to the industry $(r=.428, \mathrm{p}$-value $<0.05)$ and finally the 
professional lessons students learnt by being in contact with professionals online $(\mathrm{r}=.328$, $\mathrm{p}$-value $<0.05)$.

The low p-values (0.000) implied that work-based learning experiences significantly contributed in determining the perceived ability to perform online journalism skills among the students. As such, results suggested that the online knowledge and skills that students were exposed to and contributed during their fieldwork had a stronger determining power for the respondents' level of online journalism efficacy than the online skills they learnt from the works of other professionals. The results corroborate arguments that advocate for immersive experiential learning as the most important pathway to the development of digital skills. Through these experiences, authentic online work enables learners to create professional meaning from this direct experience in the real-world scenarios $[2,9]$.

Having determined that work-based learning experiences correlated well with online journalism efficacy, regression analysis was done to determine the statistical contribution of the mean score of the workbased learning experiences in influencing on the online journalism efficacy of the students (in the absence of other factors). The null hypothesis suggesting no significant relationship between work-based learning experiences and online journalism efficacy of mass communication students in Rwanda was tested at 95\% confidence level.

To test the hypothesis, the predicted model was fitted as $\mathrm{Y}=\beta_{0}+\beta \mathrm{X}+\varepsilon$, where $\mathrm{Y}=$ online journalism efficacy; $\beta_{0}=$ constant $(\alpha=$ constant term $) ; \beta=$ intercepts for the independent variable (work-based learning experiences); $\mathrm{X}=$ work-based learning experiences and $\varepsilon=$ error term.

Table 4 show the model goodness-of-fit used in determining the variation of students' online journalism efficacy resulting from their work-based learning experiences.

Table 4. Model summary for work-based learning experiences on online journalism efficacy ${ }^{b}$

\begin{tabular}{|l|l|l|l|l|}
\hline Model & $\mathrm{R}$ & $\mathrm{R}^{2}$ & Adjusted $\mathrm{R}^{2}$ & Std. Error \\
\hline 1 & $.527^{\mathrm{a}}$ & .278 & .272 & .477 \\
\hline
\end{tabular}

a. Predictor: (Constant), Industry experiences

b.Dependent Variable: Online journalism preparedness

The results show that model fitted well, with workbased learning experiences satisfactorily explaining the level of online journalism efficacy of the mass communication students in Rwanda. The coefficient of determination $\left(\mathrm{R}^{2}=0.278\right)$ demonstrated that $27.8 \%$ of the students' efficacy for online journalism skills could be explained by work-based learning experiences. Assuming a zero constant $\left(\beta_{0=} 0\right)$, these fieldwork experiences explained the variations in the students' online journalism efficacy by $27.2 \%$ (adjusted $\mathrm{R}^{2}=0.272$ ). Factors external to the model accounted for the remaining $72.8 \%$. The correlation coefficient between the observed and predicted values of online journalism efficacy $(R=0.527)$ indicated a strong positive correlation between online journalism efficacy levels of the students and their online experiences from the industry.

To determine if the model had a statistically significant goodness-of-fit between the work-based learning experiences and online journalism efficacy of the students (at a significance level of 5\%), ANOVA results in Table 5 , i.e. $\mathrm{F}(1,142=53.426$, p-value $<0.000)$ this significance. Since the proposed model had a statistically significant goodness-of-fit, it could be relied on to demonstrate the predictive power of workbased learning experiences on the students' efficacy for online journalism skills.

Table 5. ANOVA results for work-based learning experiences and online journalism efficacy ${ }^{\mathrm{a}}$

\begin{tabular}{|l|l|l|l|l|l|l|}
\hline \multicolumn{2}{|c|}{ Model } & SS & df & MS & F & Sig. \\
\hline \multirow{4}{*}{1} & Regression & 12.161 & 1 & 12.161 & $53.426 .000^{b}$ \\
\cline { 2 - 7 } & Residual & 31.640 & 142 & 228 & & \\
\cline { 2 - 7 } & Total & 43.801 & 143 & & & \\
\hline
\end{tabular}

a. Dependent Variable: online journalism efficacy b.Predictors: (Constant), work-based learning experiences

Key: SS=Sum of Squares; MS=Mean Squares

A test of significance of the regression of the students' work-based learning experiences and their efficacy for online journalism skills (see Table 6) revealed that a positive significant relationship existed between work-based learning experiences and online journalism efficacy $(\beta=0.411$ and $\mathrm{t}=7.309)$ with a $\mathrm{p}$ value $<0.000$.

Table 6. Coefficients for work-based learning experiences and online journalism efficacy ${ }^{\mathrm{a}}$

\begin{tabular}{|l|c|c|c|l|c|c|}
\hline \multicolumn{2}{|l|}{ Model } & \multicolumn{2}{l|}{ UC } & \multicolumn{2}{l|}{ SC } \\
\hline & & B & SE & Beta & t & Sig. \\
\hline \multirow{2}{*}{1} & Constant) & 2.647 & .202 & & 13.115 & .000 \\
\cline { 2 - 7 } & $\begin{array}{c}\text { Work-based } \\
\text { learning } \\
\text { experiences }\end{array}$ & .411 & .056 & .527 & 7.309 & .000 \\
\hline
\end{tabular}

a. Dependent Variable: Online journalism efficacy Key: UC=Unstandardized coefficients;

$\mathrm{SC}=$ Standardized coefficients; $\mathrm{SE}=$ Standard Error

This positive linear relationship implied that a unit improvement in work-based learning experiences improved the probability of the students' efficacy for online journalism skills by a factor of $0.411(41.1 \%)$, holding all other factors constant. Thus, to predict online journalism efficacy from work-based learning 
experiences $(\mathrm{X})$, as the only independent variable, the regression equation was formulated as follows:

Online journalism preparedness $(\mathrm{Y})=2.647+0.411$ (work-based learning experiences) $+\varepsilon$

With the regression coefficients showing a p-value $0.000<0.05$, the $\mathrm{H}_{0}$ was therefore rejected and a conclusion made that work-based learning experiences wielded a significant and positive influence on the efficacy for online journalism skills among mass communication students in Rwanda. These results are in congruence with Bandura's social learning theory which considers the mastery of a skill through practice as contributing to one's efficacy for performing those skills in different professional contexts [11]. Since the results showed that work-based learning experiences contributed a great proportion of online journalism efficacy among the students, this concurred with scholars like Valencia-Forrester who argued that extracurricular, field-based experiential activities provide 'work environments' that may address the inadequacies of the training institution by exposing the future professionals before they graduate [9].

\section{Discussions}

Results from this study largely confirmed the central role of work-integrated learning experiences in shaping students' beliefs in their ability to execute tasks related to online journalism upon graduation. In line with established research, it has been evident from the data that immersing students in the workings of the industry (through avenues such as internships, practicums, volunteer opportunities, etc) as part of journalistic learning bears dividends in workpreparedness. As expected, the industry experiences had the most significant positive relationship with the online journalism preparedness of the respondents. The respondents' assessment of practical online skills gained during internships, in class practicums, their personal initiatives to volunteer stories to the online news media as well as learning from the online works of their favourite professionals confirmed a strong build-up of requisite online knowledge and skills before graduation. It can therefore, be concluded that this experiential learning was key in developing the respondents' beliefs in their ability to do online journalism work.

The positive and significant correlation between online journalism skills learnt (such as use of social media tools in live news gathering) in the industry as well as participating in the development of institutional websites and social media accounts (during internships) gives credence to scholarly arguments that hands-on industry skills impart confidence among future professionals $[2,3,9]$. The majority respondents $(81.1 \%)$ who believe in these work experiences seem to attest to their value in bridging practical learning gaps that may be found in classroom teaching.

By keeping in touch with the online works of media professionals in the industry, the respondents demonstrated that published works of significant others like industry colleagues are 'professional learning sites' that cannot be ignored. For example, evidence shows that by reading or watching the new stories and comments (or audience feedback) posted by industry practitioners, future professionals may use these as yardsticks of their professional expectations once they transition to the industry [20].

At the classroom level, the teaching strategies adopted in a practical subject like journalism also determine the skills gained by students and how they transfer these to the industry [9]. For example, adopting industry-based case studies and exampled in teaching how to produce online multimedia content has been touted as an authentic learning technique where students 'learn from the pulse of the industry'. In this study, the high mean agreement level $(M=3.47)$ about the role of practicums in boosting their efficacy for online journalism skills corroborate these scholarly arguments. The same argument is extended to participation in scholarly journalism activities (e.g. online campus radio, online newspaper, etc) where around $48 \%$ of the respondents in this study indicated that they played a role in the online scholarly journalism activities at their school. Although $11 \%$ of them were not committal on their level of agreement, only a few (41\%) indicated clear disagreement. The results were not surprising since the researchers noted that scholarly journalism at the study sites was just developing, albeit with meagre online resources.

The resulting positive and significant correlations between the work-based learning experiences and the students' efficacy for online journalism skills bore clear testimony to the need for a theory-practical linkage in the journalistic learning process. This implied that the nature and types of practical online journalism skills that the students were exposed to in the field and during online journalism classes exerted a positive and significant relationship with their selfassessment of their perceived preparedness for online journalism tasks. Furthermore, the regression analysis results, which indicated that work-based learning experiences contributed to $27.8 \%$ in explaining the students' overall efficacy for online journalism skills, suggested the integral nature of this journalistic teaching and learning approach. The null hypothesis was therefore, rejected on the basis of the results that largely demonstrated the relevance of work-based experiences in building the students' efficacy for their online journalism skills $(\beta=.228$, p-value $0.000<0.05)$.

The results also gave credence to Kolb's arguments from an experiential learning theoretical framework 
[12]. By showing a strong positive relationship between the different aspects of work-based learning experiences and online journalism efficacy, the results supported Kolb's assertion that a learning approach that links theory to practical and authentic real-world scenarios makes the learners directly 'experience' the skills they are taught and therefore, assess their abilities to perform in the actual workplace.

The results had some implications for policy and practice. Since it is evident that students' perceptions of their online skills preparedness are enhanced by their exposure to industry as part of their learning, this implies the need to a deliberate and systematic embedding and scaffolding of such 'live' experiences in the online journalism curricula [20]. Industrial placement seems to uniquely contribute to the future professionals' perceptions of their capability for employment and performance. The quality and diversity of such work-based learning experiences in the context of online journalism education would determine how 'online-ready' the future professionals feel and believe. Although simulations such as case studies in classroom settings have been established as good substitutes of field experience, most scholars suggest developing strong academia-industry linkages to afford students ample opportunities for interactions and learning with and from practitioners.

To further enrich this study, future research could explore how other factors such as training content (e.g. nature and variety of online skills taught), students' online behavior and attitudes towards online tools as professional learning spaces contribute (singly or in combination) to the online journalism efficacy levels of students. The moderating influence of demographic characteristics such as students' gender, study option, digital capital and age on this relationship may also produce interesting results. A mixed methods approach is also likely to produce more comprehensive results.

\section{Conclusion}

This study explored the role of work-based learning experiences in developing students' efficacy beliefs for online journalism skills. Results largely bear out scholarly research evidence that has demonstrated a strong linkage between exposure to industry experiences and perceived work-place prepared of graduating students. About $60 \%$ of the respondents agreed $(\mathrm{M}=3.5$, S.d. $=1.25)$ that they were taught important online journalism skills while in the industry, made direct contributions in boosting online skills for the industry as well as had regular access to online works of key industry which might have provided opportunities of learning. Furthermore, the findings also indicated that more than $80 \%$ of the respondents believed in their ability to perform online journalism $\quad(\mathrm{M}=4.1, \quad$ S.d.=0.9). Further statistical analysis confirmed a positive and significant relationship between these work-based learning experiences and the students' efficacy for online journalism skills.

With the dynamic nature of the media industry especially characterized by growing convergence of the newsrooms, the study results are encouraging. They support the need to invest more efforts in designing journalism curricula that place experiential learning at their core. With industry stakeholders touting the work-based learning experiences as key in developing employable graduates, systematic integration of authentic practical experiences in a subject like online journalism are sure to not only enliven the online journalistic learning process but also help to concretize the linkage between theory learnt in class and online practice in the industry.

By demonstrating a statistically significant relationship between the work-based learning experiences and online journalism efficacy beliefs, the results brings the urgency of leveraging industry online practices on online journalism education strategies into a sharper focus. The need for sustained efforts aimed at developing a broad-based curriculum which not only delivers online journalism skills that align with industry expectations (in Rwanda and elsewhere) but also affords the future professionals to interact with the industry as they learn, is apparent from the study results.

\section{References}

[1] D. Peach, and N. Gamble, "Scoping Work-Integrated Learning purpose, practices and issues", In S. Billet and A. Henderson (eds). Developing learning professionals, 2011, 7, pp.169-186. Dordrecht, Netherlands: Springer.

[2] D. Jones, "Using digital tools in WIL to enable student journalists' real world learning”, In S. Barker, S. Dawson, A. Pardo, and C. Colvin (Eds.), Show Me The Learning. Proceedings ASCILITE 2016 Adelaide, 2016, pp. 294-299.

[3] A. Peltola, "Lead time: An examination of workplace readiness in public relations education. International Journal of Work-Integrated Learning, 2018, 19(1), pp. 37-50.

[4] A. Van Deursen, and J. van Dijk, "Internet skills and the digital divide", New Media Society, 2011, 13(6), pp. 893-911. [5] A. Ferrari, "Digital competence in practice: An analysis of frameworks", JRC Technical Reports, 2012, Institute for Prospective Technological Studies, European Union.

[6] M. Sagrista, and P. Matbob, "The digital divide in Papua New Guinea: Implications for journalism education", Pacific Journalism Review, 2016, 22(2), pp. 20-34.

[7] E. Powers, "Learning to do it all", American Journalism Review, 2012, 34(1), pp. 10-13.

[8] K. Burns, "Teaching research methods with social media", In M. Thomas (Ed.), Digital education: Opportunities for social collaboration, 2011, pp. 195-218. New York, NY: Palgrave Macmillan. 
[9] F. Valencia-Forrester, "Models of Work-Integrated Learning in Journalism Education", Journalism Studies, 2020, https://doi.org/10.1080/1461670X.2020.1719 (Access date: 16 April, 2020)

[10] C. Royal, "Developing and assessing experiential learning opportunities", Teaching Journalism and Mass Communication, 2015, 5(1), pp. 22-32.

[11] A. Bandura, "Social Cognitive Theory for Personal and Social Change by Enabling Media", In A. Singhal, M. J. Cody, E. M. Rogers, and M. Sabido (Eds.), LEA's communication series. Entertainment-education and social change: History, research, and practice, 2004, pp. 75-96.

[12] D. Kolb, "Experiential Learning: experience as the source of learning and development", 1984, Englewood Cliffs, NJ: Prentice Hall.

[13] J. Palilonis, "Research-informed Design Exercises Enhance audience Understanding among Visual communication Students", Journalism and Mass Communication Educator, 2010, pp. 414-429.

[14] Media High Council, "Media and Policy making Report”, 2018. https://paxpress.rw/IMG/pdf/how_media report policy 2.pdf (Access date: 24 April, 2020).

[15] Rwanda Governance Board, "Rwanda Media Barometer Report", 2017. www.rgb.rw/publications (Access date: 24 April, 2020).

[16] Ministry of Education, Rwanda. 2016. ICT in education yearbook. Kigali.

[17] T. Yamane (1967) Statistics, An Introductory Analysis, 2nd Ed., New York: Harper and Row, 1967.

[18] R. Faizan, and N. Zehra, "Quality Work-Life as predictor to Organizational Commitment under contrasting Leadership Styles: I.T Responses from Pakistan's private software houses", Global Journal of Management and Administration, 2016, 16(6), pp. 9-23.

[19] J. Cohen, "Quantitative methods in psychology: A power primer", Psychological Bulletin, 1992, 112(1), pp. 155-159.

[20] S. Tanner, K. Green, and S. Burns, "Experiential learning and journalism education: Special Olympics - a case study", Australian Journalism Review, 2012, 34(2), pp.115127. 